\title{
Linalool-rich Rosewood Oil Induces Vago-vagal Bradycardic and Depressor Reflex in Rats
}

\author{
Rodrigo José de Siqueira, ${ }^{1}$ Karilane Maria Silvino Rodrigues, ${ }_{2}^{1}$ Moisés Tolentino Bento da Silva, ${ }_{1}^{1}$ \\ Carlos Antônio Barros Correia Junior, ${ }^{2}$ Gloria Pinto Duarte, ${ }^{2}$ Pedro Jorge Caldas Magalhães, \\ Armênio Aguiar dos Santos, ${ }^{1}$ José Guilherme Soares Maia, \\ Pergentino José Sousa da Cunha ${ }^{4}$ and Saad Lahlou ${ }^{1 *}$ \\ ${ }^{1}$ Department of Physiology and Pharmacology, Federal University of Ceará, CE, Brazil \\ ${ }^{2}$ Department of Physiology and Pharmacology, Federal University of Pernambuco, Recife, PE, Brazil \\ ${ }^{3}$ Faculty of Food and Chemical Engineering, Federal University of Pará, Belém, PA, Brazil \\ ${ }^{4}$ Faculty of Pharmacy, Federal University of Pará, Belém, PA, Brazil
}

\begin{abstract}
Cardiovascular effects of the linalool-rich essential oil of Aniba rosaeodora (here named as EOAR) in normotensive rats were investigated. In anesthetized rats, intravenous (i.v.) injection of EOAR induced dosedependent biphasic hypotension and bradycardia. Emphasis was given to the first phase (phase 1) of the cardiovascular effects, which is rapid (onset time of 1-3 s) and not observed in animals submitted to bilateral vagotomy or selective blockade of neural conduction of vagal $\mathrm{C}$-fibre afferents by perineural treatment with capsaicin. Phase 1 was also absent when EOAR was directly injected into the left ventricle injection, but it was unaltered by i.v. pretreatment with capsazepine, ondansetron or HC030031. In conscious rats, EOAR induced rapid and monophasic hypotensive and bradycardiac (phase 1) effects that were abolished by i.v. methylatropine. In endothelium-intact aortic rings, EOAR fully relaxed phenylephrine-induced contractions in a concentrationdependent manner. The present findings reveal that phase 1 of the bradycardiac and depressor responses induced by EOAR has a vago-vagal reflex origin resulting from the vagal pulmonary afferents stimulation. Such phenomenon appears not to involve the recruitment of $\mathrm{C}$-fibre afferents expressing $\mathbf{5 H} \mathrm{H}_{3}$ receptors or the two chemosensory ion channels $T R P V_{1}$ and TRPA . Phase 2 hypotensive response appears resulting from a direct vasodilatory action. Copyright (C) 2013 John Wiley \& Sons, Ltd.
\end{abstract}

Keywords: Aniba rosaeodora Ducke; essential oil; linalool; sensory C-fibres; perineural capsaicin pretreatment; vago-vagal reflex; vascular smooth muscle.

\section{INTRODUCTION}

Aniba rosaeodora (Rosewood) var amazonica Ducke (Lauraceae) is an aromatic tree native to the rain forests in South America which trunk wood is harvested and hydrodistilled to obtain the rosewood oil. The main constituent of the essential oil of $A$. rosaeodora (EOAR) is linalool (LIN), a monoterpene alcohol, which is used in cleaning and cosmetic industry (Letizia et al., 2003). Rosewood has been also used in folk medicine for its sedative effect, an effect that was shown after inhalation in man (Sugawara et al., 1998). In human healthy volunteers, transdermal administration of LIN induced a decrease in systolic blood pressure and a smaller decrease in skin temperature without effects in subjective well-being (Heuberger et al., 2004). Furthermore, even in human subjects, inhalation of LIN also decreased heart rate (HR) and increased vagal nerve activity (Kuroda et al., 2005).

Experiments using laboratory animals showed that LIN, which is one of the major compounds of lavender

\footnotetext{
* Correspondence to: Prof. Saad Lahlou, Department of Physiology and Pharmacology, Federal University of Ceará, R. Coronel Nunes de Melo, 1127 - Rodolfo Teófilo, Fortaleza, CE, 60430-270, Brazil.

E-mail: lahlou562@gmail.com
}

essential oil, possesses sedative effects after inhalation (Elisabetsky et al., 1995). These effects could be partially explained by LIN-induced decreased neuronal excitability (Leal-Cardoso et al., 2010) and/or inhibition of adenylate cyclase (Sampaio et al., 2012). LIN also putatively mediates anti-inflammatory (Bighetti et al., 1999), gastroprotective (Hiruma-Lima et al., 2000), antileishmanial (Rosa et al., 2003) and antimicrobial (Alviano et al., 2005) effects of the essential oil of Croton cajucara. It also induces anti-inflammatory, antihyperalgesic and antinociceptive effects in rats (Peana et al., 2003) and was found to possess an anticonvulsant activity in glutamate-related seizure models (Elisabetsky et al., 1999). Olfactory stimulation with LIN elicits hypotension in anesthetized rats through activation of central histaminergic $\mathrm{H}_{3}$ receptors (Tanida et al., 2006), an effect abolished after bilateral electrolytic lesions of hypothalamic suprachiasmatic nucleus in mice (Tanida et al., 2007). Recently, hypotension in conscious rats (Menezes et al., 2010) and relaxation of rat aortic ring preparations (Baccelli et al., 2010) were reported for LIN, but the underlying mechanism involved is still unknown.

Therefore, we aimed to investigate the mechanism underlying the cardiovascular responses to intravenous (i.v.) injections of the LIN-rich EOAR in normotensive rats. In vitro experiments were also performed in aortic rings to assess whether the hypotensive response to EOAR could result from its direct vasodilator effect. 


\section{MATERIALS AND METHODS}

Plant material, essential oil composition and GC chiral analyses. Trunk wood from A. rosaeodora was collected on September 2007 near the Jatapu River, municipality of Novo Airão, State of Amazonas, Brazil. The plant was identified by comparison with an authentic voucher (MG 17,710) of $A$. rosaeodora, deposited in the herbarium of Emilio Goeldi Museum, city of Belém, State of Pará, Brazil. EOAR was obtained from dried trunk wood by hydrodistillation in Clevenger-type apparatus ( $3 \mathrm{~h})$, as previously described (Sampaio et al., 2012). The oil was dried over anhydrous sodium sulfate, and its percentage content was calculated on the basis of the plant dry weight. EOAR was also analyzed in a gas chromatography (GC) chiral column for the quantification of the enantiomers (-)-LIN and (+)-LIN. Individual components were identified by comparison of both mass spectrum and their retention time with those existing in the data system libraries and cited in the literature.

Solutions and drugs. For in vivo experiments, EOAR was dissolved in Tween 80 (2\%), brought to the chosen volume with sterile isotonic saline under sonication. EOAR and capsaicin were injected manually as a bolus in a volume of $0.1 \mathrm{~mL}$, followed by a $0.2 \mathrm{~mL}$ flush with physiological saline. Capsaicin was used for the perineural treatment of the vagus at a concentration of $250 \mu \mathrm{g} / \mathrm{mL}$ and prepared in $1 \%$ Tween $80,1 \%$ ethanol and $98 \%$ saline. For i.v. injection, a solution of capsaicin at a desired concentration was prepared daily by dilution with saline on the basis of an animal's body weight. Methylatropine bromide, HC030031 and ondansetron were dissolved in saline just before use and administered in a volume of $1 \mathrm{~mL} / \mathrm{kg}$ body weight. Capsazepine was first diluted in dimethyl sulphoxide to $0.1 \mathrm{~mol} / \mathrm{L}$ ( $37 \mathrm{mg} / \mathrm{mL}$ ) and further diluted with saline containing $10 \%$ Tween 80 and $10 \%$ ethanol to a final concentration of $1 \mathrm{mg} / \mathrm{mL}$. For in vitro experiments, EOAR was first dissolved in Tween $80(0.5 \%)$, made up with the perfusion medium and sonicated just before use whereas acetylcholine was first dissolved in distilled water and was brought to volume with the perfusion medium. The perfusion medium used was fresh Krebs-Henseleit solution (KHS) ( $\mathrm{pH} 7.4)$ of the following composition (in mM): $\mathrm{NaCl} 118 ; \mathrm{KCl} 4.7 ; \mathrm{NaHCO}_{3} 25 ; \mathrm{CaCl}_{2} \cdot 2 \mathrm{H}_{2} \mathrm{O}$ 2.5; $\mathrm{KH}_{2} \mathrm{PO}_{4} 1.2 ; \mathrm{MgSO}_{4} .7 \mathrm{H}_{2} \mathrm{O} 1.2 ;$ glucose 11 and EDTA 0.01. Drugs were purchased from Sigma (St Louis, USA) and Tocris (Ballwin, USA).

\begin{abstract}
Animals. Male Wistar rats (280-320 g) were kept under standard conditions (temperature at $22 \pm 2{ }^{\circ} \mathrm{C} ; 12 \mathrm{~h}$ light/ $12 \mathrm{~h}$ dark cycle and food and water ad libitum). All animals were cared for in compliance with the Guide for the Care and Use of Laboratory Animals, published by the US National Institutes of Health (NIH Publication 85-23, revised 1996). Prior approval from local animal ethics committee (number 11043896-5) was obtained.
\end{abstract}

In vivo experiments. Catheterization procedure. Rats were anesthetized with sodium pentobarbital $(50 \mathrm{mg} / \mathrm{kg}$, i.p.), and catheters (PE-10 fused PE-50) were implanted in the abdominal aorta (for blood pressure recording) and in the inferior vena cava (for drug administration) through the left femoral artery and vein, respectively, as previously described (de Siqueira et al., 2006a). In some animals $(n=4)$, a catheter was inserted on the day of experiment into the right carotid artery and advanced retrogradely until its tip was positioned in the left ventricle. Its position was confirmed by measurement of left ventricular blood pressure and postmortem examination. Postoperatively, rats received an intramuscular injection of penicillin (24,000 IU). They were housed individually in plastic cages and allowed to recover for $24 \mathrm{~h}$ before any circulatory experiments.

Recording of mean arterial pressure and HR. At the time of experiment, rats were again anesthetized with sodium pentobarbital $(50 \mathrm{mg} / \mathrm{kg}$, i.p.). A short tracheal cannula was inserted via a tracheotomy, through which rats breathed spontaneously in the supine position. Baseline mean arterial pressure (MAP) and HR values were recorded on a Gilson model $5 / 6 \mathrm{H}$ (medical Electronics Inc., Middletown, WI, USA), as previously described (de Siqueira et al., 2006b, 2010).

Experimental design and protocols. In order to explore the cardiovascular responses to EOAR, the following protocol was used. Before each experiment, a period of 15-20 min was allowed to obtain a stable MAP and HR tracing. Injection response times were measured from the end of an injection to the onset of bradycardia. Injections were separated by $10 \mathrm{~min}$ intervals in order to avoid tachyphylaxis. Doses of agonists and antagonists were chosen according to those recommended in the literature. The following series of experiments, except series 8 (conscious rats), were performed in anesthetized rats.

In a first series of experiments which was carried out to establish a dose-effect relationship, each animal received a series of increasing bolus doses of EOAR $(1,5,10$ and $20 \mathrm{mg} / \mathrm{kg}$, i.v. $)$, and time course of the changes in MAP and HR was recorded (Series $1, n=7$ ). In five different groups of rats, maximal changes in MAP and HR elicited by i.v. injection of EOAR $(20 \mathrm{mg} / \mathrm{kg})$ were determined before and after a cervical bilateral vagotomy (Series 2, $n=6)$; before and after bilateral perineural treatment $(\mathrm{PNT})$ with capsaicin $(250 \mu \mathrm{g} / \mathrm{mL})$ (de Siqueira et al., 2006b, 2010) of both cervical vagi (Series $3, n=4)$; before and after i.v. pretreatment with competitive $\mathrm{TRPV}_{1}$ receptor antagonist, capsazepine $(1 \mathrm{mg} / \mathrm{kg})$ (Malinowska et al., 2001) (Series 4, $n=5$ ); before and after i.v. pretreatment with the $\mathrm{TRPA}_{1}$ antagonist, $\mathrm{HC} 030031$ $(8 \mathrm{mg} / \mathrm{kg}$ ) (Lin et al., 2010) (Series $5, n=4)$ and before and after the pretreatment with the $5-\mathrm{HT}_{3}$ receptor antagonist, ondansetron $(30 \mu \mathrm{g} / \mathrm{kg})$ (Bagchi and Deshpande, 1999) (Series 6, $n=5$ ). To determine the location of the afferent C-fibre endings involved in the cardiovascular responses, EOAR $(20 \mathrm{mg} / \mathrm{kg})$ was injected into the left ventricle bypassing therefore the pulmonary circulation and presumably do not have immediate access to the pulmonary C-fibres (Series 7, $n=4$ ).

The last series of experiments (Series 8) was performed in conscious rats in order to assess the role of cholinergic mechanism in the mediation of EOAR-induced cardiovascular changes. Therefore, maximal changes in MAP and HR elicited by EOAR (10 and $20 \mathrm{mg} / \mathrm{kg}$, i.v.) were determined in conscious rats that had been pretreated intravenously $10 \mathrm{~min}$ earlier with vehicle $(1 \mathrm{~mL} / \mathrm{kg}$, 
$n=7$ ), or the peripheral muscarinic receptor antagonist methylatropine $(1 \mathrm{mg} / \mathrm{kg}, n=6)$ (de Siqueira et al., 2006a).

In vitro experiments. Rats were sacrificed and thoracic aortae were removed and cut into rings which were mounted in $5-\mathrm{mL}$ organ baths containing gassed $(5 \%$ $\mathrm{CO}_{2}$ in $\mathrm{O}_{2}$ ) KHS, at $37^{\circ} \mathrm{C}$ ( $\left.\mathrm{pH} 7.4\right)$. Passive tension was $1 \mathrm{~g}$, and contractions were recorded using an isometric force transducer (Grass Model FTO3, Quincy, MA, USA) connected to a PC-based Dataq acquisition system (PM-1000, CWE Inc., Akron, OH, USA). The vasorelaxant activity was studied according by constructing concentration-effect curves in response to cumulative addition of EOAR $(0.15-771.25 \mu \mathrm{g} / \mathrm{mL})$. Data were expressed as a percentage of the contraction induced by phenylephrine (PHE, $0.1 \mathrm{M}$ ).

Statistical analysis. All results are expressed as the mean \pm SEM. Maximal changes in MAP and HR were expressed as a percentage of baseline values. $\mathrm{IC}_{50}$ value was calculated by interpolation from semi-logarithmic plots. Significance of results $(p<0.05)$ was assessed by paired Student's $t$-test, Mann-Whitney U-test and oneor two-way analysis of variance (ANOVA), followed by Dunnett's or Holm-Sidak's multiple comparison tests when appropriate.

\section{RESULTS}

Rosewood oil showed a yield of $1.5 \%$ with a colourless to pale yellow liquid with a woody-floral fragrance. Its analysis by GC and GC-mass spectrometry showed the following composition: $\operatorname{LIN}(87.7 \%$, in a racemic mixture of $50.62 \%(-)$-LIN and $49.38 \%(+)$-LIN in a GC chiral column analysis), $\alpha$-terpineol $(3.1 \%)$, geraniol $(1.2 \%)$, trans-LIN oxide $(0.8 \%)$, cis-LIN oxide $(0.7 \%)$ and minor sesquiterpenes $(4.7 \%)$. In anesthetized rats, baseline MAP and HR before injection of each dose of EOAR remained essentially invariant $(p>0.05)$. Therefore, mean values of MAP and HR in this group of animals before any pretreatment were $109.3 \pm 2.1 \mathrm{mmHg}$ and $367 \pm 9$ beats/min, respectively (pooled data from 24 rats).

\section{In vivo experiments}

Injections of EOAR (1-20 mg/kg, i.v.) but not its vehicle elicited dose-dependent (Fig. 1, $p<0.001$ ) hypotensive and bradycardiac effects that became significant (Fig. 1, $p<0.05)$ at $1 \mathrm{mg} / \mathrm{kg}$. At 10 and $20 \mathrm{mg} / \mathrm{kg}$ of EOAR, the hypotensive (Figs. 1A and 2A) and bradycardiac (Fig. 1B and $2 \mathrm{~B}$ ) responses to EOAR were biphasic. As shown in Fig. 2 (panels A and B), the first rapid component of EOAR-induced bradycardia and hypotension (phase 1) occurred at 1-2 and 2-3s after injection, respectively, while the second and more lasting component of EOAR-induced bradycardia and hypotension (phase 2) picked at 4-7 and 6-11s after injection, respectively. Phase 2 hypotensive response to 10 and $20 \mathrm{mg} / \mathrm{kg}$ EOAR remained statistically significant $(p<0.05)$ at $1 \quad(-37.37 \pm 4.65$ and $-59.1 \pm 3.34 \%$, respectively), $3(-31.23 \pm 6.17$ and $-49.04 \pm 9.31 \%$,
EOAR (mg/kg)
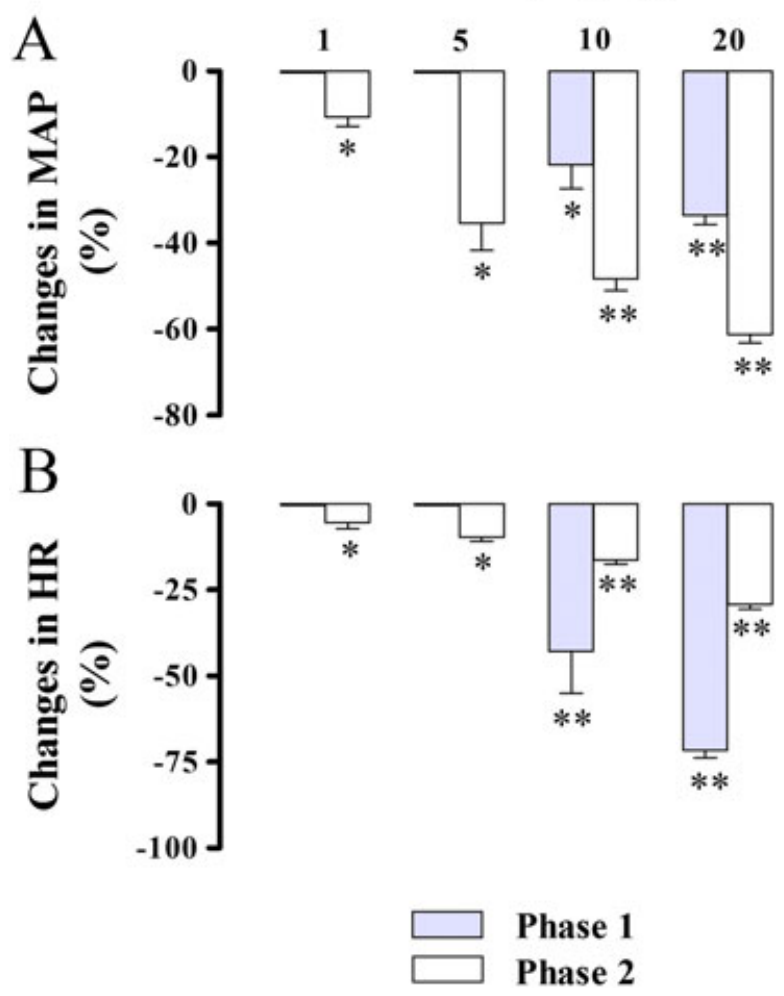

Figure 1. Maximal decreases in mean arterial pressure (MAP) (A) and heart rate (HR) (B) induced by intravenous injection of the essential oil of Aniba rosaeodora (EOAR, $1-20 \mathrm{mg} / \mathrm{kg}$ ) in anesthetized rats. Biphasic (phases 1 and 2) hypotensive and bradycardiac effects were more evident at 10 and $20 \mathrm{mg} / \mathrm{kg}$. Data are mean \pm SEM and expressed as percentage of baseline $(n=7) .{ }^{*} p<0.05$ and ${ }^{*} p<0.01$ by paired Student's $t$-test $v s$. the corresponding baseline values.

respectively) and $5(-16.19 \pm 4.73$ and $-27.97 \pm 10.74 \%$, respectively) min after the administration. Likewise, phase 2 bradycardic response to 10 and $20 \mathrm{mg} / \mathrm{kg}$ EOAR also remained statistically significant $(p<0.05)$ at 1 $(-16.55 \pm 3.63$ and $-31.36 \pm 1.01 \%$, respectively), 3 $(-16.02 \pm 3.11$ and $-30.54 \pm 4.06 \%$, respectively) and 5 $(-12.79 \pm 2.96$ and $-30.78 \pm 8.38 \%$, respectively) $\min$ after the administration. The profile of the cardiovascular responses induced by EOAR was comparable to the triphasic changes in MAP (effects a, b and c; Fig. 2E) and biphasic bradycardia (effects $f$ and s; Fig. 2F) induced by capsaicin $(10 \mu \mathrm{g} / \mathrm{kg}$, i.v. $)$.

When injected directly into the left ventricle, EOAR $(20 \mathrm{mg} / \mathrm{kg}$ ) did not evoke the rapid hypotension (Fig. 2C) and bradycardia (Fig. 2D) responses (phase 1), but induced a delayed and significant $(p<0.01)$ systemic hypotension $(-58.41 \pm 5.05 \%$, baseline $\mathrm{MAP}=105.3 \pm$ $8.7 \mathrm{mmHg}$ ) (Fig. 2C) and bradycardia $(-24.0 \pm 3.0 \%$, baseline HR $=375 \pm 8$ beats $/ \mathrm{min}$ ) (Fig. 2D) that occurred with a latency similar $(15.80 \pm 0.53$ and $13.08 \pm 0.77 \mathrm{~s}$, respectively) as that observed for the hypotension and bradycardia (phase 2) elicited by i.v. EOAR ( 6-11 and $\sim 4-7$ s, respectively).

Phase 1 of hypotensive and bradycardiac responses to EOAR was abolished $(p<0.001)$ by either bivagotomy or PNT with capsaicin while it was unaltered by capsazepine, ondansetron and HC030031 pretreatments (Fig. 3, panels A and B). By contrast, phase 2 hypotensive and bradycardiac responses to EOAR (Fig. 3, panels C and D, 

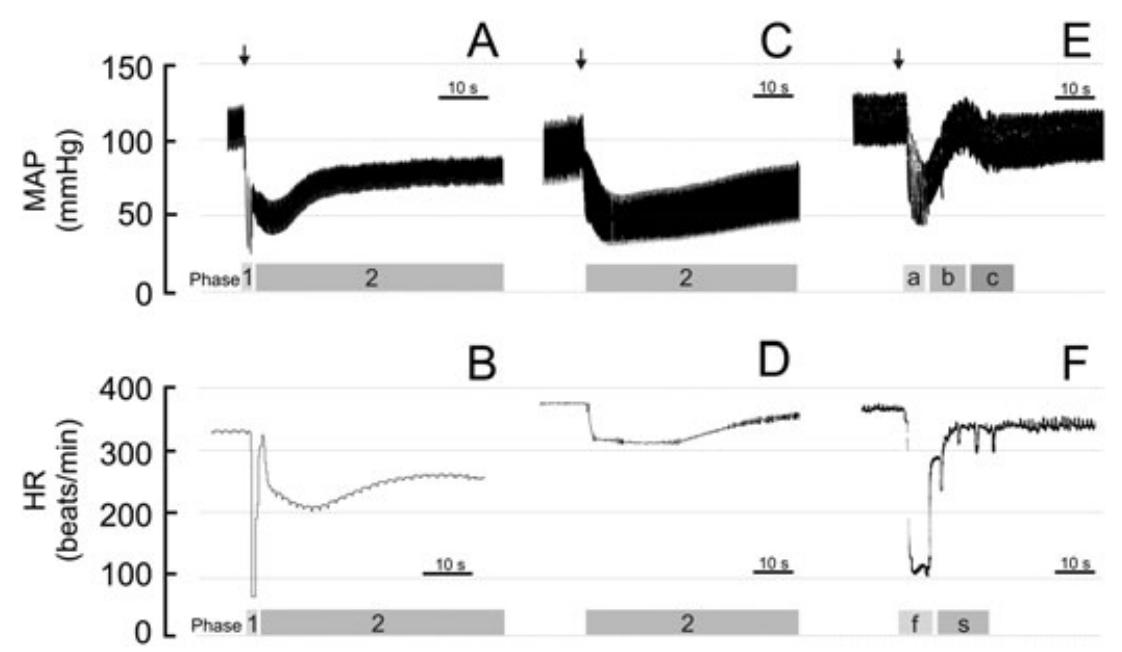

Figure 2. Representative recordings showing changes in mean arterial pressure (MAP) and heart rate (HR) induced by intravenous injection of the essential oil of Aniba rosaeodora (EOAR, $20 \mathrm{mg} / \mathrm{kg}$ ) (panels A and B, respectively) or capsaicin ( $10 \mu \mathrm{g} / \mathrm{kg}$ ) (panels E and F, respectively) in anesthetized rats without any pretreatment. Panels $\mathbf{C}$ and $\mathbf{D}$ correspond to representative recordings showing changes in MAP and HR evoked by EOAR $(20 \mathrm{mg} / \mathrm{kg})$ injected into the left ventricle. Arrows indicate the time of injection. a, b, c: typical triphasic changes in blood pressure following capsaicin injection; $f(f a s t)$ and $s$ (slow): biphasic bradycardia following capsaicin injection. Panels $E$ and $F$ match the ones that were previously reported (de Siqueira et al., 2010).

respectively) remained unchanged by all pretreatments. In conscious rats, EOAR (10 and $20 \mathrm{mg} / \mathrm{kg}$, i.v.) evoked significant (Fig. 4, $p<0.001$ ), rapid and monophasic decreases in MAP and HR (phase 1, latency 1.7-3.2 s) which was abolished by methylatropine pretreatment (Fig. 4).
As previously reported (de Siqueira et al., 2006a,2006b; Lahlou et al., 2007), baseline MAP and HR values remained significantly unchanged following bolus i.v. injection of the same volume $(100 \mathrm{~L})$ of the EOAR's vehicle in conscious rats $(-0.61 \pm 1.05$ and
Phase 1

(A)

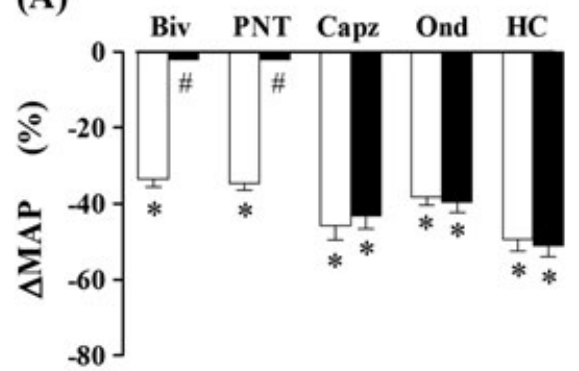

Phase 1

(B)

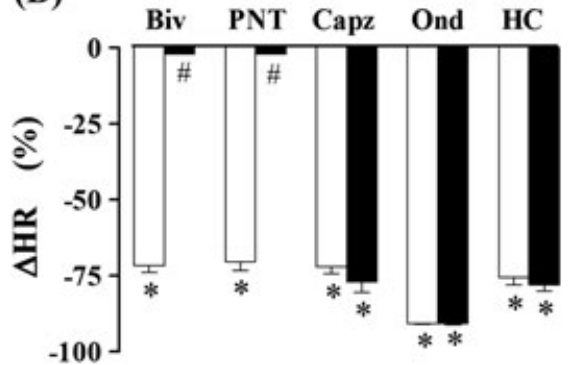

Phase 2

(C)

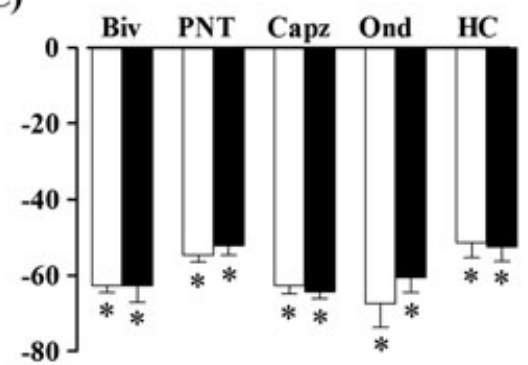

Phase 2

(D)

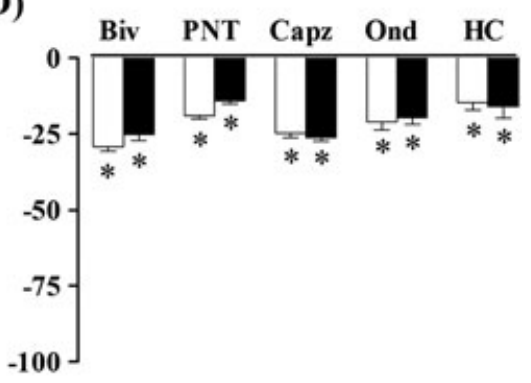

\section{Before treatment}

After treatment

Figure 3. Phase 1 decreases in mean arterial pressure $(\triangle M A P)$ and heart rate $(\triangle H R)$ (panels $\mathbf{A}$ and $\mathbf{B}$, respectively) and phase 2 hypotensive and bradycardiac effects (panels $\mathbf{C}$ and D, respectively) elicited by intravenous (i.v.) administration of the essential oil of Aniba rosaeodora (EOAR, $20 \mathrm{mg} / \mathrm{kg}$ ) in five groups of anesthetized normotensive rats: (1) before and after bivagotomy (Biv) at cervical level ( $n=6)$, (2) before and after perineural treatment (PNT) of both cervical vagi with capsaicin $(250 \mu \mathrm{g} / \mathrm{mL}, n=5)$, (3) before and after i.v. pretreatment with capsazepine (Capz; $1 \mathrm{mg} / \mathrm{kg}, n=4)$, (4) before and after i.v. pretreatment with ondansetron $(0 \mathrm{Ond} ; 30 \mu \mathrm{g} / \mathrm{kg}, n=5)$ and $(5) \mathrm{before}$ and after i.v. pretreatment with $\mathrm{HC} 0300031$ (HC; $8 \mathrm{mg} / \mathrm{kg}, n=4)$. Data are mean $\pm \mathrm{SEM}$ and expressed as percentage of baseline. ${ }^{*} p<0.01$ and ${ }^{\#} p<0.05$ by paired Student's $t$-test $v s$. the baseline values and the corresponding responses before any pretreatment, respectively. 


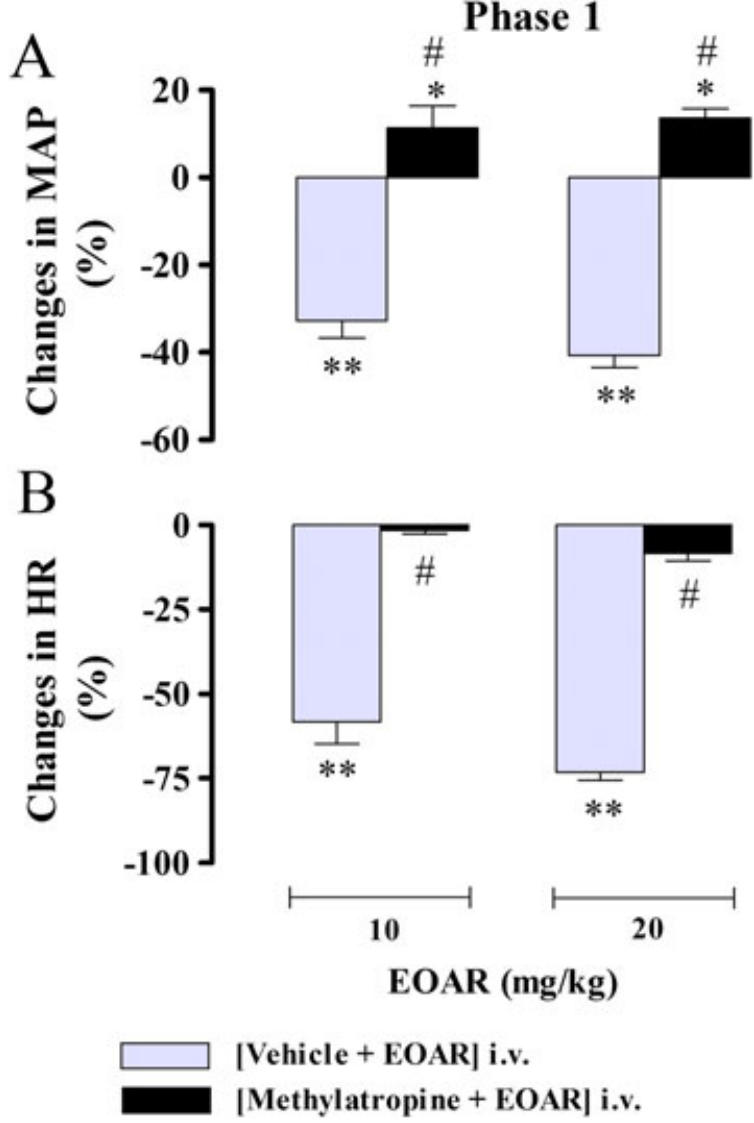

Figure 4. Maximal changes in mean arterial pressure (MAP) (A) and heart rate (HR) (B) elicited by intravenous administration of essential oil of Aniba rosaeodora (EOAR, 10 and $20 \mathrm{mg} / \mathrm{kg}$ ) in conscious normotensive rats pretreated with vehicle or methylatropine ( $1 \mathrm{mg} / \mathrm{kg}$, i.v.). Data are mean $\pm \mathrm{SEM}$ and expressed as percentage of baseline ( $n=6-7$ rats per group). ${ }^{*} p<0.05$ and ${ }^{*}{ }^{*} p<0.01$ by paired Student's $t$-test $v s$. the corresponding baseline values; ${ }^{\#} p<0.001$ by Mann-Whitney U-test with respect to vehiclepretreated rats.

$2.30 \pm 1.50 \%$, respectively; $n=3)$ as well as in intact $(0.43 \pm 0.47$ and $2.70 \pm 2.60 \%$, respectively; $n=3)$ or bivagotomized $(-0.84 \pm 1.33$ and $0.87 \pm 0.95 \%$, respectively; $n=3$ ) anesthetized, rats.

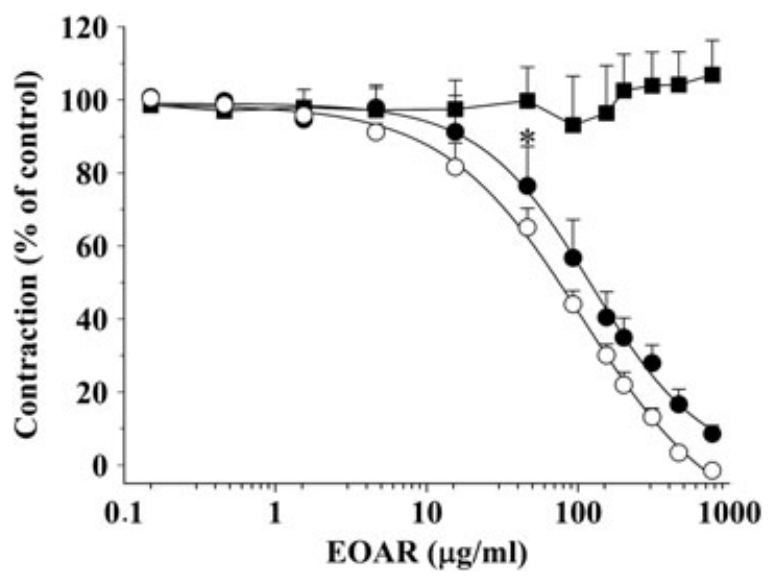

Figure 5. Vascular effects of increasing concentrations $(0.15-$ $7771.25 \mu \mathrm{g} / \mathrm{mL}$ ) of the essential oil of Aniba rosaeodora (EOAR) on the contraction induced by phenylephrine (PHE, $0.1 \mathrm{M})$ in aortic ring preparations with (solid circles) or without (open circles) functional endothelium. Data are mean \pm SEM and expressed as percentage of PHE-induced contractions ( $n=5-6$ per group). ${ }^{*}$ First significant effect by $p<0.01$, two-way ANOVA followed by Holm-Sidak test with respect to vehicle (solid rectangles).

\section{In vitro experiments}

In aortic preparations with intact endothelium, EOAR (0.15-771.25 $\mu \mathrm{g} / \mathrm{mL})$ relaxed the PHE-induced contractions in a concentration-dependent manner (Fig. 5; $p<0.001$ ) with an $\mathrm{IC}_{50}$ (geometric mean [95\% confidence interval]) value of 95.08 [36.32-153.8] $\mu \mathrm{g} / \mathrm{mL}$. The first significant effect was observed at $46 \mu \mathrm{g} / \mathrm{mL}$ EOAR (Fig. 5; $p<0.01$ ). EOAR-induced vasorelaxant effects were reversible after wash and remained unaffected by the endothelium removal (Fig. 5, $\mathrm{IC}_{50}=72.35$ [43.13-101.6] $\mu \mathrm{g} / \mathrm{mL}$ ). Vehicle had no effect on PHE-induced contractions in either endothelium-containing (Fig. 5) or denuded aortic preparations (data not shown).

\section{DISCUSSION}

In this study, i.v. administration of EOAR (at 10 and $20 \mathrm{mg} / \mathrm{kg}$ ) induced two periods of hypotension and bradycardia in anesthetized rats. Initially, a rapid bradycardia (onset time of 1-2s) occurred coincidentally (onset time of 2-3s) with an arterial hypotension (phase 1 ), and then a delayed and more lasting decrease in blood pressure associated with a second bradycardia (phase 2). Phase 1 responses occurred as rapidly as the vago-vagal reflex elicited by i.v. capsaicin (Donnerer and Lembeck, 1982; Yang et al. 1993) or serotonin (Owen et al., 2005). Therefore, we investigated the possibility that EOAR could induce a capsaicin- or serotonin-like bradycardiac and depressor reflex.

This study focused on phase 1 hypotensive and bradycardiac responses to EOAR. This phase was abolished in bivagotomized, anesthetized rats and by pretreatment with methylatropine in conscious rats. This indicates that this phase is mediated by a vagal reflex and an efferent cholinergic mechanism. The finding that PNT with capsaicin of both cervical vagi, a well-known method to produce a selective blockade of neural conduction of vagal C-fibre afferents (Jancsó and Such, 1983), also prevented the phase 1 responses indicates that EOAR stimulates vagal sensory $\mathrm{C}$-fibres to elicit vago-vagal reflex decreases in HR and blood pressure. It seems unlikely that EOAR activates vagal sensory C-fibres indirectly via its metabolites because of the too short latency of the EOAR-induced reflex response. EOARinduced initial bradycardia and hypotensive effects (phase 1) seem to result from stimulation of pulmonary C-fibre afferents as it was absent after left ventricle injection. It is known that activation of these afferents by various chemical agents induces the transient systemic hypotension that accompanies the reflex bradycardia (Coleridge and Coleridge, 1984).

An attempt has been made to assess the receptor specificity of the EOAR-induced bradycardiac and depressor reflex. Our results suggest that neither vanilloid $\mathrm{TRPV}_{1}$ nor $5-\mathrm{HT}_{3}$ receptors are involved in the mediation of EOAR-induced phase 1 vagus reflex, as it remained unchanged by capsazepine (Bevan et al., 1992) and ondansetron, respectively. Recently, it was reported that that LIN stimulates TRPA 1 receptors in dissociated dorsal root ganglia (Riera et al., 2009), and stimulation of TRPA receptors with i.v. cinnamaldehyde elicited immediate 
and short hypotensive and bradycardiac effects (BezoldJarisch-like reflex) in the anesthetized mouse (Pozsgai et al., 2010). However, the present in vivo study showed that TRPA 1 antagonist HC030031 failed to alter the vagus reflex evoked by EOAR which may suggest that this reflex is independent of the direct action of EOAC on $\mathrm{TRPA}_{1}$ receptors. It is noteworthy that the importance of this novel superfamily of receptors, their actual location and their pathophysiology relevance in the cardiovascular regulation are still limited. The second hypotensive response (phase 2) to i.v. EOAR seems resulting from its direct vasodilatory effect on the peripheral smooth muscle because (i) EOAR relaxed PHE-induced contractions in endothelium-intact aortic rings, (ii) a hypotensive response was also observed after left ventricle injection of EOAR and was not abolished by either bilateral vagotomy or PNT with capsaicin and finally (iii) EOARinduced phase 2 hypotension was more potent on diastolic arterial blood pressure (Fig. 2C) suggesting that it is mainly due to decreased peripheral vascular resistance.

The EOAR sample used herein contains LIN as the major constituent ( $87 \%$ of the total oil). Since its inhalation in volunteers decreased HR and increased vagal nerve activity (Kuroda et al., 2005), it seems highly probable that LIN is the active principal that mediate the cardiovascular responses to EOAR. Further experiments are needed to corroborate this hypothesis and also to assess whether a pure enantiomer (e.g. (-)-LIN) could display a greater efficacy in inducing vagus reflex than the racemic mixture $( \pm)$-LIN. However, putative partial involvement of other minor constituents in the mediation of EOAR-induced vago-vagal reflex cannot be excluded. Furthermore, both in vitro and in vivo effects of the EOAR were reversible excluding therefore the possibility that they might have related to a putative toxic effects of the EOAR. In fact, LIN could be classified in the group of slightly toxic substances on the basis of classification of chemical substance because its $\mathrm{LD}_{50}$ value of oral acute toxicity in rats was found greater than $2500 \mathrm{mg} / \mathrm{kg}$ (Jenner et al., 1964; Letizia et al., 2003). The present study is of pharmacological relevance. It contributes to the little systematic studies with particular reference to hypotensive activity of $A$. rosaedora. Further studies are needed to be conducted in hypertensive rats which could indicate potential application of this plant to treat hypertension in humans.

In conclusion, EOAR induces a vago-vagal bradycardiac and depressor reflex (phase 1) in anesthetized rat that appears initiated in pulmonary rather than cardiac vagal afferent fibres. The transduction mechanism of the EOAR excitation of C-fibre endings is not fully understood and seems not to involve the activation of either vallinoid $\mathrm{TRPV}_{1}, \mathrm{TRPA}_{1}$ or $5-\mathrm{HT}_{3}$ receptors located on vagal sensory nerves. The second hypotensive response (phase 2) to i.v. EOAR seems to result from a direct and endothelium-independent vasodilatory effect of EOAR on the peripheral vascular smooth muscle.

\section{Acknowledgements}

This research was supported by fellowships from the 'Coordenação de Aperfeiçoamento de Pessoal de Nível Superior' (CAPES) to KMS Rodrigues and MTB da Silva, Ph.D. students and to RJB de Siqueira (postdoctoral fellowship).

\section{Conflict of Interest}

The authors declare no conflict of interest.

\section{REFERENCES}

Alviano WS, Mendonça-Filho RR, Alviano DS, et al. 2005. Antimicrobial activity of Croton cajucara Benth linalool-rich essential oil on artificial biofilms and planktonic microorganisms. Oral Microbiol Immunol 20: 101-105.

Baccelli C, Martinsen A, Morel N, Quetin-Leclerq J. 2010. Vasorelaxant activity of essential oils from Croton zambesicus and some of their constituents. Planta Med 76: 1506-1511.

Bagchi S, Deshpande SB. 1999. Indian red scorpion (Buthus tamulus) venom-induced augmentation of cardiac reflexes is mediated through the involvement of peripheral $5-\mathrm{HT}_{3}$ and central 5-HT 1 A receptor subtypes. Toxicon 37: 1697-1709.

Bevan S, Hothi S, Hughes G, et al. 1992. Capsazepine: A competitive antagonist of the sensory neurone excitant capsaicin. Br J Pharmacol 107: 544-552.

Bighetti EJ, Hiruma-Lima CA, Gracioso JS, Brito AR. 1999. Antiinflammatory and antinociceptive effects in rodents of the essential oil of Croton cajucara Benth. J Pharm Pharmacol 51: 1447-1453.

Coleridge JCG, Coleridge HM. 1984. Afferent vagal C fibre innervation of the lungs and airways and its functional significance. Rev Physiol Biochem Pharmacol 99: 1-110.

de Siqueira RJ, Leal-Cardoso Couture, R. Lahlou S. 2006a. Role of capsaicin-sensitive sensory nerves in mediation of the cardiovascular effects of the essential oil of Croton zehntneri leaves in anaesthetized rats. Clin Exp Pharmacol Physiol 33: 238-247.

de Siqueira RJ, Macedo FI, Interaminense LF, et al. 2010. 1-Nitro2-phenylethane, the main constituent of the essential oil of Aniba canelilla, elicits a vago-vagal bradycardiac and depressor reflex in normotensive rats. Eur J Pharmaco/ 638: 90-98.

de Siqueira RJ, Magalhães PJ, Leal-Cardoso JH, Duarte GP, Lahlou S. 2006b. Cardiovascular effects of the essential oil of Croton zehntneri leaves and its main constituents, anethole and estragole, in normotensive conscious rats. Life Sci 78: 2365-2372.

Donnerer J, Lembeck F. 1982. Analysis of the effects of intravenously injected capsaicin in the rat. Naunyn Schmiedebergs Arch Pharmacol 320: 54-57.

Elisabetsky E, Brum LF, Souza DO. 1999. Aniconvulsant properties of linalool in glutamate-related seizure models. Phytomedicine 6: 107-113.

Elisabetsky E, Coelho de Souza GP, dos Santos MAC, Siquieira IR, Amador TA. 1995. Sedative properties of linalool. Fitoterapia 46: 407-414.

Heuberger E, Redhammer S, Buchbauer G. 2004. Transdermal absorption of (-)-linalool induces autonomic deactivation but has no impact on ratings of well-being in humans. Neuropsychopharmacology 29: 1925-1932.

Hiruma-Lima CA, Gracioso JS, Rodriguez JA, Haun M, Nunes DS, Souza Brito AR. 2000. Gastroprotective effect of essential oil from Croton cajucara Benth. (Euphorbiaceae). J Ethnopharmacol 69: 229-234.

Jancsó G, Such G. 1983. Effects of capsaicin applied perineurally to the vagus nerve on cardiovascular and respiratory functions in the cat. J Physiol 341: 359-370.

Jenner PM, Hagan EC, Taylor JM. 1964. Food flavorings and compounds of related structure I. Acute oral toxicity. Food Chem Toxicol 2: 327-343.

Kuroda K, Inoue N, Ito $Y$, et al. 2005. Sedative effects of the jasmine tea odor and (R)-(-)-linalool, one of its major odor components, on autonomic nerve activity and mood states. Eur $J$ App/ Physiol 95: 107-114.

Lahlou S, de Barros Correia CA Jr, Vasconcelos Dos Santos M, et al. 2007. Mechanisms underlying the cardiovascular effects of a labdenic diterpene isolated from Moldenhawera nutans in normotensive rats. Vascul Pharmacol 46: 60-66. 
Leal-Cardoso JH, da Silva-Alves KS, Ferreira-da-Silva FW, et al. 2010. Linalool blocks excitability in peripheral nerves and voltage-dependent $\mathrm{Na}^{+}$current in dissociated dorsal root ganglia neurons. Eur J Pharmacol 645: 86-93.

Letizia CS, Cocchiara J, Lalko J, Api AM. 2003. Fragrance material review on linalool. Food Chem Toxicol 41: 943-964.

Lin YS, Hsu CC, Bien MY, hsu HC, Weng HT, Kou YR. 2010. Activations of TRPA $_{1}$ and $\mathrm{P} 2 \mathrm{X}$ receptors are important in ROSmediated stimulation of capsaicin-sensitive lung vagal afferents by cigarette smoke in rats. J Appl Physiol 108: 1293-1303.

Malinowska B, Kwolek G, Gothert M. 2001. Anandamide and methanandamide induce both vanilloid VR1 - and cannanbinoid CB1 receptor mediated changes in heart rate and blood pressure in anaesthetized rats. Naunyn Schmiedebergs Arch Pharmacol 364: 562-569.

Menezes IA, Barreto CM, Antoniolli AR, Santos MR, de Sousa DP. 2010. Hypotensive activity of terpenes found in essential oils. Z Naturforsch C 65: 562-566.

Owen JA, Bates JN, Lewis SJ. 2005. Endogenous nitrosyl factors may inhibit the desensitization of $5-\mathrm{HT}_{3}$ receptors on vagal cardiopulmonary afferents. Brain Res 1059: 167-172.

Peana AT, D'Aquila PS, Chessa ML, Moretti MD, Serra G, Pippia P. 2003. (-)-Linalool produces antinociception in two experimental models of pain. Eur J Pharmacol 460: 37-41.

Pozsgai G, Bodkin JV, Graepel R, Bevan S, Andersson DA, Brain SD. 2010. Evidence for the pathophysiological relevance of
TRPA 1 receptors in the cardiovascular system in vivo. Cardiovasc Res 87: 760-768.

Riera C, Menozzi-Smarrito C, Affolter M, Michlig S, Munari C, Robert F, Vogel H, Simon SA, le Couture J. 2009. Compounds from Sichuan and Melegueta peppers activate, covalently and non-covalently, TRPA1 and TRPV1 channels. Br J Pharmacol 157: 1398-1409.

Rosa MSS, Mendonça-Filho RR, Bizzo HR, et al. 2003. Antileishmanial activity of a linalool-rich essential oil from Croton cajucara. Antimicrob Agents Chemother 47: 1895-1901.

Sampaio LF, Maia JG, de Parijós AM, de Souza RZ, Barata LE. 2012 Linalool from rosewood (Aniba rosaeodora Ducke) oil inhibits adenylate cyclase in the retina, contributing to understanding its biological activity. Phytother Res 26: 73-77.

Sugawara Y, Hara C, Tamura K, et al. 1998. Sedative effect on humans of inhalation of essential oil of linalool: sensory evaluation and physiological measurements using optically active linalools. Analyt Chim Acta 365: 293-299.

Tanida M, Nijima A, Shen J, Nakamura J, Nagai K. 2006. Olfactory stimulation with scent of lavender oil affects autonomic neurotransmission and blood pressure in rats. Neurosci Lett 398: 155-160.

Tanida M, Yamatodani A, Nijima A, Shen J, Todo T, Nagai K. 2007. Autonomic and cardiovascular responses to scent stimulation are altered in cry KO mice. Neurosci Lett 413: 177-182.

Yang JM, Wu SN, Chen LI. 1993. Spinal adenosine modulates capsaicin-induced depressor reflex: involvement of adenosine $A_{2}$ receptor. Gen Pharmacol 24: 961-970. 